\title{
Glutamatergic Contributions to Nicotinic Acetylcholine Receptor Agonist-Evoked Cholinergic Transients in the Prefrontal Cortex
}

\author{
Vinay Parikh, ${ }^{1}$ Kingson Man, ${ }^{1}$ Michael W. Decker, ${ }^{2}$ and Martin Sarter ${ }^{1}$ \\ ${ }^{1}$ Department of Psychology, University of Michigan, Ann Arbor, Michigan 48109-1043, and ²Neuroscience Research, Abbott Laboratories, Abbott Park, \\ Illinois 60064-6125
}

\begin{abstract}
Because modulation of cortical cholinergic neurotransmission has been hypothesized to represent a necessary mechanism mediating the beneficial cognitive effects of nicotine and nicotinic acetylcholine receptor (nAChR) subtype-selective agonists, we used choline-sensitive microelectrodes for the real-time measurement of ACh release in vivo, to characterize cholinergic transients evoked by nicotine and the $\alpha 4 \beta 2^{*}$-selective nAChR partial agonist 2-methyl-3-(2-(S)-pyrrolindinylmethoxy)pyridine dihydrochloride (ABT-089), a clinically effective cognition enhancer. In terms of cholinergic signal amplitudes, ABT-089 was significantly more potent than nicotine in evoking ACh cholinergic transients. Moreover, cholinergic signals evoked by ABT- 089 were characterized by faster signal rise time and decay rate. The nAChR antagonist mecamylamine attenuated the cholinergic signals evoked by either compound. Cholinergic signals evoked by ABT-089 were more efficaciously attenuated by the relatively $\beta 2^{*}$-selective nAChR antagonist dihydro- $\beta$-erythroidine. The $\alpha 7$ antagonist methyllycaconitine did not affect choline signal amplitudes but partly attenuated the relatively slow decay rate of nicotine-evoked cholinergic signals. Furthermore, the AMPA receptor antagonist DNQX as well as the NMDA receptor antagonist APV more potently attenuated cholinergic signals evoked by ABT-089. Using glutamate-sensitive microelectrodes to measure glutamatergic transients, ABT-089 was more potent than nicotine in evoking glutamate release. Glutamatergic signals were highly sensitive to tetrodotoxin-induced blockade of voltage-regulated sodium channels. Together, the present evidence indicates that compared with nicotine, ABT-089 evokes more potent and sharper cholinergic transients in prefrontal cortex. Glutamatergic mechanisms necessarily mediate the cholinergic effects of nAChR agonists in the prefrontal cortex.
\end{abstract}

Key words: nicotine; acetylcholine; ABT-089; glutamate; choline/glutamate-sensitive microelectrodes; cognition

\section{Introduction}

The specific neuronal mechanisms responsible for the beneficial cognitive effects of nicotinic acetylcholine receptor (nAChR) agonists have remained unclear. Based primarily on the predominance of presynaptic nACh heteroreceptors in the forebrain (Wonnacott 1997), including cortex, nAChR stimulation influences the release of several neurotransmitters, including dopamine, glutamate, noradrenaline, as well as ACh (Quirion et al., 1994; Marchi and Raiteri, 1996; Summers et al., 1997; Marchi et al., 1999; Girod et al., 2000; Lambe et al., 2003; Risso et al., 2004; Turner, 2004; Cao et al., 2005; Grilli et al., 2005; Rousseau et al., 2005; Shearman et al., 2005; Dani and Bertrand, 2007). Because of evidence indicating that cortical ACh release mediates attentional

Received Nov. 27, 2007; revised Jan. 11, 2008; accepted Feb. 26, 2008.

This work was supported by a grant from Abbott Laboratories and Public Health Service Grant MH080332. We thank Dr. Clark Briggs (Abbott Laboratories) for his comments on a draft of this manuscript. We also thank Drs. Greg Gerhardt, Francois Pomerleau, and Peter Huettl (University of Kentucky, Lexington, KY) for their continued technical support.

M.W.D. declares that ABT-089 is a compound under clinical development at Abbott Laboratories.

Correspondence should be addressed to Martin Sarter, Department of Psychology, University of Michigan, 530 Church Street, 4032 East Hall, Ann Arbor, MI 48109-1043. E-mail: msarter@umich.edu.

DOI:10.1523/JNEUROSCI.5251-07.2008

Copyright $\odot 2008$ Society for Neuroscience $\quad$ 0270-6474/08/283769-12\$15.00/0 performance (McGaughy et al., 1996; Gill et al., 2000; Dalley et al., 2004; Apparsundaram et al., 2005; Sarter et al., 2005, 2006; Kozak et al., 2006; Parikh et al., 2007), the enhancement of attentional functions and capacities by nAChR agonists has been hypothesized to be caused by increases in cortical ACh release (McGaughy et al., 1999; Hernandez and Terry, 2005).

The present focus on evoked cholinergic transients was informed by evidence indicating that in the medial prefrontal cortex (mPFC), such transients underlie the detection of cues in attentional contexts. The present research tested the general hypothesis that nAChR agonists evoke cholinergic transients that mirror the fast rise time $(<1 \mathrm{~s})$ and fast decay rate (mean $t_{50}, 3.17 \mathrm{~s}$ ) of cholinergic transients mediating cue detection (Parikh et al., 2007). This research tested the effects of local infusions of receptor ligands because, as already mentioned, local heteroreceptors mediate the effects of these drugs on neurotransmitter release. As we observed previously that the amplitude of rapidly decaying cholinergic transients predicted the efficacy with which cues controlled the animals' behavior (Parikh et al., 2007), the analyses of drug-evoked cholinergic transients focused on amplitude and decay rate. The overall rationale of this research was guided by the hypothesis that the characterization of drug-evoked cholinergic transients in anesthetized animals serves as an initial in vivo screening approach for putative cognition enhancers. 
The focus on comparisons between the cholinergic effects of nicotine and the $\alpha 4 \beta 2^{\star}$-selective agonist 2-methyl-3-(2-(S)pyrrolindinylmethoxy)pyridine dihydrochloride (ABT-089) was based on the beneficial cognitive effects of ABT-089 in adults with attention deficit hyperactivity disorder (Wilens et al., 2006; Wilens and Decker, 2007). The cognition enhancer ABT-089 (Decker et al., 1997) was classified as a $\alpha 4 \beta 2^{\star}$-selective nAChR agonist based on high affinity and selectivity to this receptor subtype (Sullivan et al., 1997). Moreover, partial agonism at this receptor was deduced based on the relatively low efficacy of ABT089, when compared with nicotine, in stimulating $\left[{ }^{86} \mathrm{Rb}^{+}\right]$efflux from cells expressing human $\alpha 4 \beta 2^{\star}$ nAChRs (Sullivan et al., 1997; Rueter et al., 2004).

To measure cholinergic transients, at a scale of seconds, we used choline-sensitive microelectrodes to monitor choline that results from hydrolysis of ACh. This method was demonstrated to provide a sensitive and valid measure of newly released $\mathrm{ACh}$, at a scale of seconds (Burmeister and Gerhardt, 2001; Burmeister et al., 2002; Parikh et al., 2004, 2006, 2007; Parikh and Sarter, 2006).

\section{Materials and Methods}

Subjects. Adult male Fisher/Brown Norway hybrid rats (FBNF1; Harlan, Indianapolis, IN; $n=144$ ), weighing $200-250 \mathrm{~g}$ at the beginning of the experiments were used. Animals were treated in accordance with the guidelines of the University Committee on the Use and Care of Animals at the University of Michigan and housed in facilities accredited by the American Association of Accreditation of Laboratory Animal Care. Food and water were available ad libitum (Rodent Chow; Harlan Teklad, Madison, WI).

Drugs and chemicals. Choline oxidase (ChOase) (EC 1.1.3.17), bovine serum albumin (BSA), glutaraldehyde, ascorbic acid (AA), dopamine (DA), choline, L-glutamic acid, nicotine, mecamylamine (MEC), neostigmine, 6,7-dinitroquinoxaline-2,3-dione (DNQX), $R$-2-amino-5phosphono-pentanoate (APV), methyllycaconitine (MLA), and tetrodotoxin (TTX) were obtained from Sigma (St. Louis, MO). Dihydro- $\beta$ erythroidine $(\mathrm{DH} \beta \mathrm{E})$ was obtained from Tocris Bioscience (Ellisville, MO). ABT-089 was provided by Abbott Laboratories (Abbott Park, IL). Glutamate oxidase (GO; EC 1.4.3.11) was procured from Seikagaku America (East Falmouth, MA). Meta-phenylene diamine ( $m$-PD) was obtained from Fluka Biochemika (Buchs, Switzerland). HPLC grade water (Fisher Scientific, Davis, CA) was used to prepare all solutions. Solutions used for intracranial injections were prepared in $0.9 \% \mathrm{NaCl}, \mathrm{pH}$ 7.4, and filtered through $0.22 \mu \mathrm{m}$ sterile nonpyrogenic filters (Costar, Corning, NY) before use.

Preparation and calibration of choline-sensitive microelectrodes. Ceramic-based, multisite microelectrodes featuring four $15 \times 333 \mu \mathrm{m}$ platinum $(\mathrm{Pt})$ recording sites arranged in side-by-side pairs (Quanteon, Nicholasville, KY) (see Fig. 1a) were coated with ChOase as described previously (Parikh et al., 2004; Parikh and Sarter, 2006). Briefly, ChOase was cross-linked with the BSA-glutaraldehyde mixture and immobilized onto the bottom pair of recording sites. The remaining two recording sites were coated only with the BSA-glutaraldehyde solution and served to record background activity. ChOase-coated microelectrodes were airdried for $48-72 \mathrm{~h}$ before use. Afterward, $m$-PD was electropolymerized onto the microelectrodes to enhance the selectivity for choline by preventing access of potential electroactive interferents, including AA and catecholamines, to the Pt recording sites (Mitchell, 2004; Bruno et al., 2006). $m$-PD electroplating was performed by applying a constant voltage of $0.5 \mathrm{~V}$ to the microelectrode against a $\mathrm{Ag} / \mathrm{AgCl}$ reference electrode (Bioanalytical Systems, West Lafayette, IN) in a beaker containing a solution of $5 \mathrm{~mm} m$-PD and $10 \mu \mathrm{m}$ AA (in $0.05 \mathrm{~m}$ PBS, PBS), bubbled with nitrogen gas and maintained at $37^{\circ} \mathrm{C}$ for $60 \mathrm{~min}$. AA and nitrogen gas served to protect $m$-PD from oxidation. The $m$-PD plated ChOasecoated microelectrodes were soaked in $0.05 \mathrm{M}$ PBS for $30 \mathrm{~min}$ before calibration. Calibrations were performed using fixed potential amperometry by applying a constant voltage of $0.7 \mathrm{~V}$ versus $\mathrm{Ag} / \mathrm{AgCl}$ reference electrode in a beaker containing a stirred solution of $0.05 \mathrm{M} \mathrm{PBS}(40 \mathrm{ml})$ maintained at $37^{\circ} \mathrm{C}$ using a FAST-16 electrochemical system (Quanteon). Amperometric currents were digitized at a frequency of $5 \mathrm{~Hz}$. After achieving a stable baseline current, aliquots of stock solutions of AA (20 $\mathrm{mm})$, choline $(20 \mathrm{~mm})$, and DA (2 $\mathrm{mm})$ were added to the calibration beaker such that the final concentrations were $250 \mu \mathrm{M} \mathrm{AA}, 20,40,60$, and $80 \mu \mathrm{M}$ choline and $2 \mu \mathrm{M}$ DA (see Fig. $1 b$ ). The slope (sensitivity), limit of detection (LOD) and linearity $\left(R^{2}\right)$ for choline, as well as selectivity ratio for AA, was calculated for individual recording sites. To be used in subsequent in vivo experiments, electrodes were required to meet the following characteristics: sensitivity for detecting choline on ChOase-coated channels, $>3 \mathrm{pA} / \mu \mathrm{M}$, with a background current of $200 \mathrm{pA}$ on all recording sites; LOD $<300 \mathrm{~nm}$ choline; ratio of selectivity for choline and AA, $>80: 1$; detection of increasing choline concentrations $(20-80 \mu \mathrm{M})$ on ChOase-coated platinum recording sites, $R^{2}>0.98$; negligible changes in current on all recording channels after DA addition $(<3 \mathrm{pA})$.

In vivo recording of cholinergic signals. Animals were anesthetized with urethane $(1.25-1.5 \mathrm{~g} / \mathrm{kg}$, i.p.) and placed in a stereotaxic frame (model 962; David Kopf Instruments, Tujunga, CA). The body temperature of animals was maintained at $37^{\circ} \mathrm{C}$ using an isothermal delta-phase pad (Braintree Scientific, Braintree, MA) during the entire experimental session. Single-barrel glass capillaries $(1.0 \times 0.58 \mathrm{~mm}, 6$ inches; A-M Systems, Everett, WA) were pulled using a micropipette puller (model 51210; Stoelting, Wood Dale, IL) and then bumped against a glass slide to attain an inner tip diameter of $\sim 15 \mu \mathrm{m}$. The micropipette attached to the ceramic platform of the calibrated ChOase-coated microelectrode using sticky wax (Kerr, Romulus, MI) such that the tip of the micropipette was placed between the lower and upper pair of recording sites. The spacing between the tip of the micropipette and the microelectrode was maintained at 70-100 $\mu \mathrm{m}$. $\mathrm{An} \mathrm{Ag} / \mathrm{AgCl}$ reference electrode prepared from a miniature silver wire (200 $\mu \mathrm{m}$ diameter) was implanted at a site remote from the recording area. The micropipette was loaded with one of the test solutions (see below, Experimental design) before microelectrode implantation. The microelectrode/micropipette assembly was slowly lowered into the $\mathrm{mPFC}$ (anteroposterior, $+3.0 \mathrm{~mm}$; mediolateral, $-0.7 \mathrm{~mm}$; dorsoventral, $-3.0 \mathrm{~mm}$, measured from bregma) using a microdrive (MO-10; Narishige International, East Meadow, NY) (for an illustration of the microelectrode placement in the mPFC) (see Fig. $1 \mathrm{~A}$ ). Electrodes were placed between layers III and V, the two layers receiving thalamic input (Kuroda et al., 1995). Drug solutions were ejected from the micropipettes using polytetrafluoroethylene tubing connected to a pressure ejection system (Picospritzer III; Parker Hannifin, Fairfield, NJ), at 2-10 psi for 1-2 s. The ejected volumes were monitored using a stereomicroscope (Meiji Techno America, San Jose, CA) fitted with a reticule (Friedemann and Gerhardt 1992). A fixed potential of $+0.7 \mathrm{~V}$ was applied to the microelectrode and amperometric recordings were made every second and digitized using the FAST-16 system. After microelectrode implantation, experiments were initiated after $60 \mathrm{~min}$, when a stable baseline current was achieved.

Experimental design. The experimental design used to determine ACh release and underlying neuropharmacological mechanisms after the administration of $\mathrm{nAChR}$ agonists is illustrated in Figure $2 a$. The effects of nicotine and ABT-089 on mPFC cholinergic activity were evaluated by measuring changes in cholinergic signal levels after a series of intracranial pressure ejections of either drug (40 and 200 pmol, and 4 and $20 \mathrm{nmol}$; drug was a between-subject variable). The concentrations for the $\mathrm{AChR}$ agonists were calculated on the basis of the volume of ejections $(200 \mathrm{nl})$ of $200 \mu \mathrm{M}$, and 1, 20, and $100 \mathrm{~mm}$ solutions. To determine the effects of mecamylamine, neostigmine, DNQX, DH $\beta \mathrm{E}, \mathrm{MLA}$, or APV on nicotine/ ABT-089-evoked cholinergic signals, solution of these drugs or vehicle were slowly infused ( $800 \mathrm{nl}$ over $5 \mathrm{~s}$ ) after the first three pressure ejections of a nAChR agonist. Thereafter, a second series of three pressure ejections of the agonist was conducted (see Fig. 2a). The effects of the acetylcholinesterase (AChE) inhibitor neostigmine $(20 \mathrm{nmol})$ were determined to verify that nAChR-partial agonist-induced increases in choline signal levels reflect choline resulting from hydrolysis of newly released ACh from cholinergic terminals (Parikh et al., 2004). The effects of the noncompetitive $\mathrm{nAChR}$ antagonist mecamylamine $(80 \mathrm{pmol})$, the relatively $\beta 2^{\star}$-selective $\mathrm{nAChR}$ antagonist DH $\beta \mathrm{E}(1.6 \mathrm{nmol}$ ) (Harvey et al., 1996; Harvey and Luetje 1996), and the $\alpha 7$-selective antagonist MLA (80, 800 
pmol) were assessed in separate experiments. The concentrations for mecamylamine and $\mathrm{DH} \beta \mathrm{E}$ were based on pilot data indicating $\sim 80 \%$ inhibition of nicotine- and ABT-089-evoked cholinergic signal amplitudes, respectively (see Results). Based on evidence suggesting nAChRmediated modulation of thalamocortical inputs and glutamate release (Gioanni et al., 1999; Lambe et al., 2003), and NMDA and AMPA receptor-mediated stimulation of cortical ACh release (Ulus et al., 1992; Pittaluga et al., 2006), the effects of the AMPA receptor antagonist DNQX (20, 80, 200, $800 \mathrm{pmol})$ and the NMDA antagonist APV (40 pmol) on nicotine or ABT-089-evoked cholinergic transients were determined. Finally, in a separate series of experiments, the effects of nAChR agonists on glutamate release were determined using glutamate-oxidase coated microelectrodes (below).

In this context, it should be noted that nicotine and ABT-089 exhibit comparable lipophilicity as indicated by their similar $c \log p$ and $\mathrm{pKa}$ values (Dr. William H. Bunnelle, Abbott Laboratories, personal communication).

Choline signal analyses. As described previously, choline signals recorded via ChOase-coated sites were corrected by signals recorded on non-ChOase-coated recordings sites ("self-referencing"), if choline signals were associated with relatively high background noise levels $(>2$ $\mu \mathrm{M})$ or artifacts resulted from pressure ejection. Because $m$-PD electropolymerized electrodes completely lacked sensitivity for DA (see Fig. $1 b$ ), currents recorded from non-ChOase-coated sites were simply subtracted from currents recorded via ChOase-coated sites.

Cholinergic signals were analyzed with respect to peak amplitudes, signal rise time (time from pressure ejection to peak signal amplitude) and signal decay rate $\left(t_{50}\right.$; time required for the signal to decline by $50 \%$ from peak amplitude). The effects of antagonists and neostigmine on nicotine or ABT-089-evoked choline signals were compared with signals evoked by pressure ejections of nicotine or ABT-089 subsequently to the infusion of saline (see Fig. 2a). The averages of three responses per drug manipulation and per animal were used for statistical analyses.

In vivo recording of glutamate release. To record changes in extracellular glutamate concentrations, glutamate-sensitive microelectrodes were prepared by immobilizing GO onto recording channels as described previously (Burmeister et al., 2002). Briefly, 100 nl of enzyme solution containing 1\% GO, 1\% BSA and $0.125 \%$ glutaraldehyde was applied to the bottom pair of recording sites. Non-GO platinum recording sites were coated with enzyme-free solution ( $1 \%$ BSA and $0.125 \%$ glutaraldehyde). The coatings were air-dried and allowed to cure for $48-72 \mathrm{~h}$ at room temperature. On the day of experiment, the GO-coated microelectrodes were electroplated with $m$-PD. These electrodes were then calibrated as discussed above (for ChOase-coated microelectrodes) except that L-glutamic acid $(20-80 \mu \mathrm{M})$ was added into the bath solution instead of choline (for in vitro calibration data, see Results). The criteria for using GO-coated microelectrodes for in vivo glutamate recordings were similar to ChOase-coated electrodes. Glutamate-sensitive microelectrodes were implanted in the mPFC of anesthetized rats and glutamate recordings were performed at $1 \mathrm{~Hz}$. The experimental design for glutamate recordings was identical to that illustrated in Figure 2. The effects of nicotine and ABT-089 were tested at the two lower doses (40 pmol or $200 \mathrm{pmol}$ ) that revealed differences in cholinergic activity (see Fig. $3 c$ ). Furthermore, mecamylamine-induced attenuation of nAChR agonist-evoked glutamate signals was determined. Finally, to determine whether nAChR agonist-induced increases in glutamate levels are of neuronal origin, the effects of $\mathrm{Na}^{+}$channel blocker TTX ( $\left.80 \mathrm{pmol}\right)$ were determined. Glutamate signals were analyzed as described above for choline signals.

Histological methods. After completion of electrochemical recordings, animals were transcardially perfused with $100 \mathrm{ml}$ of ice-cold heparinized saline followed by $300 \mathrm{ml}$ of $4 \%$ paraformaldehyde in $0.1 \mathrm{M} \mathrm{PBS}$, pH 7.4. The brains were removed and postfixed overnight at $4^{\circ} \mathrm{C}$ and stored in $30 \%$ sucrose in $0.1 \mathrm{~m}$ PBS for $72 \mathrm{~h}$. Coronal sections $(50 \mu \mathrm{m})$ were cut using a freezing microtome (CM 2000R; Leica, Chantilly, VA) and stored in cryoprotectant solution (15\% glucose, 30\% ethylene glycol, and $0.04 \%$ sodium azide in $0.05 \mathrm{M}$ PBS, pH 7.4) at $20 \mathrm{C}$ until further processing. Serial sections were Nissl-stained to determine the placement of microelectrodes.

Statistical analyses. Statistical analyses were conducted using SPSS/
PC+ version 13.0 (SPSS, Chicago, IL). Repeated-measures mixed-factor ANOVAs were used to analyze the effects of drug (nicotinic agonists; two levels), saline infusion (two levels), and dose (four levels) on cholinergic signal amplitudes. Likewise, the effects of nicotinic partial agonist (two levels), saline treatment (two levels), and dose (two levels) on glutamate signal amplitudes were analyzed using repeated-measure ANOVAS. Mixed factor ANOVAs were used to compare the effects of nicotine and ABT-089 on choline or glutamate signals. Post hoc multiple comparisons were conducted using the least significant difference (LSD) test. To compare the effects of pharmacological manipulations on nicotine- or ABT089-evoked choline or glutamate signals, one-way ANOVAs were used, followed by LSD tests or planned two-tailed unpaired Student's $t$ tests. Exact $p$ values are reported as recommended by Greenwald et al. (1996).

\section{Results}

\section{In vitro calibration of choline-sensitive microelectrodes}

ChOase-coated recording channels displayed linear increases in current in response to successive additions of choline (Fig. 1b). Addition of AA produced negligible currents at ChOase- as well as non-ChOase-coated sites. Likewise, addition of DA did not produce any measurable changes in current (Fig. 1b), indicating the effectiveness of the $m$-PD electroplating procedure in preventing $\mathrm{DA}$ from reaching the Pt recording sites.

ChOase-coated microelectrodes used in the present experiments $(n=100)$ exhibited a sensitivity of $7.78 \pm 0.04 \mathrm{pA} / \mu \mathrm{M}$ of choline, with a background current of $125.48 \pm 0.01 \mathrm{pA}$. The LOD was $220.85 \pm 15.44 \mathrm{nM}, R^{2}$ was $0.993 \pm 0.001$, the and selectivity of choline:AA was $396.33 \pm 112.71$.

\section{Cholinergic signals evoked by nicotine and ABT- 089}

\section{Effects of repeated pressure ejections of $n A C h R$ agonists}

As illustrated in Figure $2 a$, antagonists, TTX, or neostigmine were infused before a second series of pressure ejections of the nAChR agonists. To control for the effects of repeated pressure ejections of the agonists, the effects of saline infusions on choline signals evoked by repeated pressure ejections of the agonists were determined. Compared with the effects of the presaline series of three pressure ejections of nicotine or ABT-089 (Fig. 2, drug was a between-subject variable), cholinergic signals evoked by the second series of three pressure ejections of nicotine or ABT-089 were characterized by a small but significant reduction in peak amplitude [main effect of repeated pressure ejections (first vs second series): $F_{(1,23)}=4.35, p=0.048$; series $\times$ drug: $F_{(1,1)}=0.61, p=$ 0.44 ; series by dose: $F_{(1,3)}=0.71, p=0.56$; series $\times$ drug $\times$ dose: $F_{(3,23)}=0.44, p=0.73$ ] (Fig. 2b). We also analyzed signal decay rates to evaluate the possibility that increases in the capacity of the high-affinity choline transporter (CHT) contributed to the small reduction in signal amplitude observed during the second administration series. However, signal decay rate did not differ between the two administration series $\left(t_{50}\right.$; first series: $33.67 \pm$ $16.75 \mathrm{~s}$; second: $35.67 \pm 15.18 \mathrm{~s} ; p>0.3)$. Therefore, CHT upregulation unlikely contributed to the small decrease in amplitude observed during the second administration series. Furthermore, continuous exposure of electrodes to nicotine or ABT-089 did not affect electrode properties, as was determined by incubating choline-sensitive microelectrodes in vitro in nicotine or ABT089 (100 mM) for $30 \mathrm{~min}$, followed by recalibration. Finally, we also excluded the possibility that repeated pressure ejections of solutions per se influenced peak amplitudes, perhaps by altering the composition and structure of the neuronal space. Pressure ejections of relatively large volumes $(1000 \mathrm{nl})$ did not further augment the effects of repeated administration on signal amplitudes (data not shown). Because the reduction of amplitudes was observed to recover after $30 \mathrm{~min}$ (data not shown), the small 
reduction in amplitude in response to the second series of pressure ejections of the nAChR agonists may be speculated to reflect rapid and transient desensitization of nAChRs (Robinson et al., 2007). Importantly, the effects of the antagonists, neostigmine and TTX were compared against choline signals evoked by the second series of pressure ejections of the nAChR agonists.

Additional analyses concerned the variability of the effects of repeated pressure ejections of the nAChR ligands during the second series of applications, in part because of the planned averaging of the amplitudes of three signals obtained after additional pharmacological manipulations. As illustrated in Figure 2, $c$ and $d$, repeated pressure ejection did not produce systematic effects on choline signal amplitudes and there were no interactions between the effects of repeated pressure ejection and concentration of nicotine and ABT-089 (main effect of repeated ejection: $F_{(2,40)}=$ $2.88, p=0.07$; ejection $\times$ concentration: $\left.F_{(6,40)}=0.33, p=0.92\right)$.

Cholinergic signals evoked by nicotine and $A B T-089$

Compared with the cholinergic transients evoked by nicotine, ABT-089 was more potent with respect to signal amplitudes (for justification of the focus on signal amplitudes, see Introduction). Furthermore, cholinergic transients evoked by ABT-089 were characterized by faster rise times and decay rates. Figure 3, $a$ and $b$, shows representative choline signal traces in response to pressure ejections of nicotine (4 nmol) and ABT-089 ( $4 \mathrm{nmol}$ ), illustrating the different dynamics of choline signals evoked by the two compounds.

Nicotine and ABT-089 (40 pmol to 20 nmol) produced concentrationdependent increases in choline signal amplitudes $\left(F_{(3,23)}=3.43, p=0.03\right)$ (Fig. $3 c$ ). After pressure ejections of 40 and 200 pmol, ABT-089 produced significantly greater amplitudes than nicotine (Fig. $3 c$ ) (40 pmol: $t_{(9)}=2.60 ; 200$ pmol: $t_{(8)}=$ 2.58; both $p<0.05)$. Higher concentrations of nicotine and ABT-089 (4 and 20 nmol) resulted in equivalent peak amplitudes (both $p>0.05$ ). A semilog plot depicting dose-response curves for nicotine and ABT-089-evoked cholinergic signal amplitudes is illustrated in Figure $3 f$ [curves were generated by fitting the data to a three-parameter sigmoidal function (Motulsky and Ransnas, 1987); note that to generate this function, the effects of a smaller concentration of ABT-089, 4 pmol, needed to be determined; see the data point located closest to the ordinate]. $\mathrm{ED}_{50}$ values for nicotine and ABT-089 were 1.48 and $0.047 \mathrm{nmol}$, respectively.

Compared with cholinergic signals elicited by nicotine, ABT-
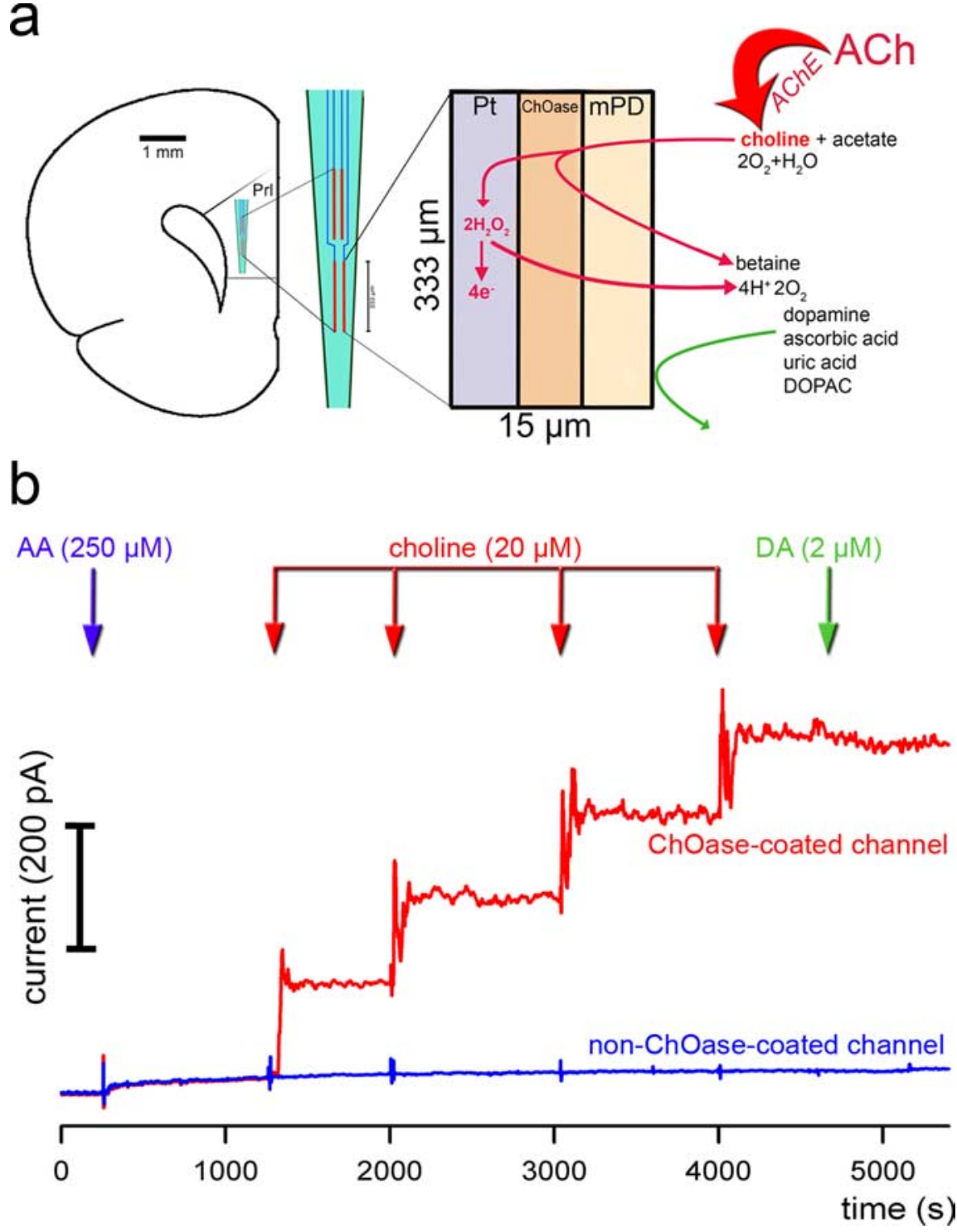

Figure 1. $\quad \boldsymbol{a}$, Schematic illustration depicting the choline-sensitive microelectrode for measurement of cholinergic activity. On the right, the ceramic-based microelectrode with four Pt recordings sites and the main principles of the measurement scheme are illustrated. Choline is generated by hydrolysis of newly released ACh via AChE. The lower pair of recording sites was coated with Ch0ase, whereas the upper pair was not coated with Ch0ase and used for self-referencing. $m$-PD electropolymerization served to repel electroactive interferents including DA, $A A$, uric acid, and DOPAC (3,4-dihydroxyphenylacetic acid) from the surface of the platinum recording sites. Hydrogen peroxide $\left(\mathrm{H}_{2} \mathrm{O}_{2}\right)$ is generated as a result of choline oxidation and measured using fixed potential amperometry. The left insert illustrates the placement and approximate relative dimensions of the microelectrode when placed into the prelimbic (Prl) area of the mPFC. $\boldsymbol{b}$, In vitro calibration of a Ch0ase-coated microelectrode. Raw current traces recorded from a Ch0ase-coated (red) and non-Ch0ase-coated (blue) channel are shown. Currents in response to the successive addition of AA, choline, and DA indicate the sensitivity of the ChOase-coated channel to choline, but not to AA and DA.

089-evoked signals were characterized by faster rise times and decay rates (Fig. $3 a, b, d, e$ ) (main effects of drug: rise time, $F_{(1,42)}=$ 22.22, $p<0.001$; decay rate, $\left.t_{50}, F_{(1,42)}=18.25, p<0.001\right)$. As illustrated in Figure $3 d$, increasing concentrations of nicotine resulted in increased signal rise times. In contrast, signal rise times produced by ABT-089 remained short and unaffected by concentration (nicotine: $F_{(3,18)}=5.84, p=0.006$; ABT-089: $F_{(3,18)}=$ $0.91, p=0.45)$. Likewise, the decay of cholinergic signals was not sensitive to the concentration of ABT-089 $\left(F_{(3,18)}=0.86, p=\right.$ $0.48)$, whereas higher concentrations of nicotine resulted in slower signal decay rates $\left(F_{(3,18)}=4.67, p=0.014\right)$ (Fig. $3 e$ ). 

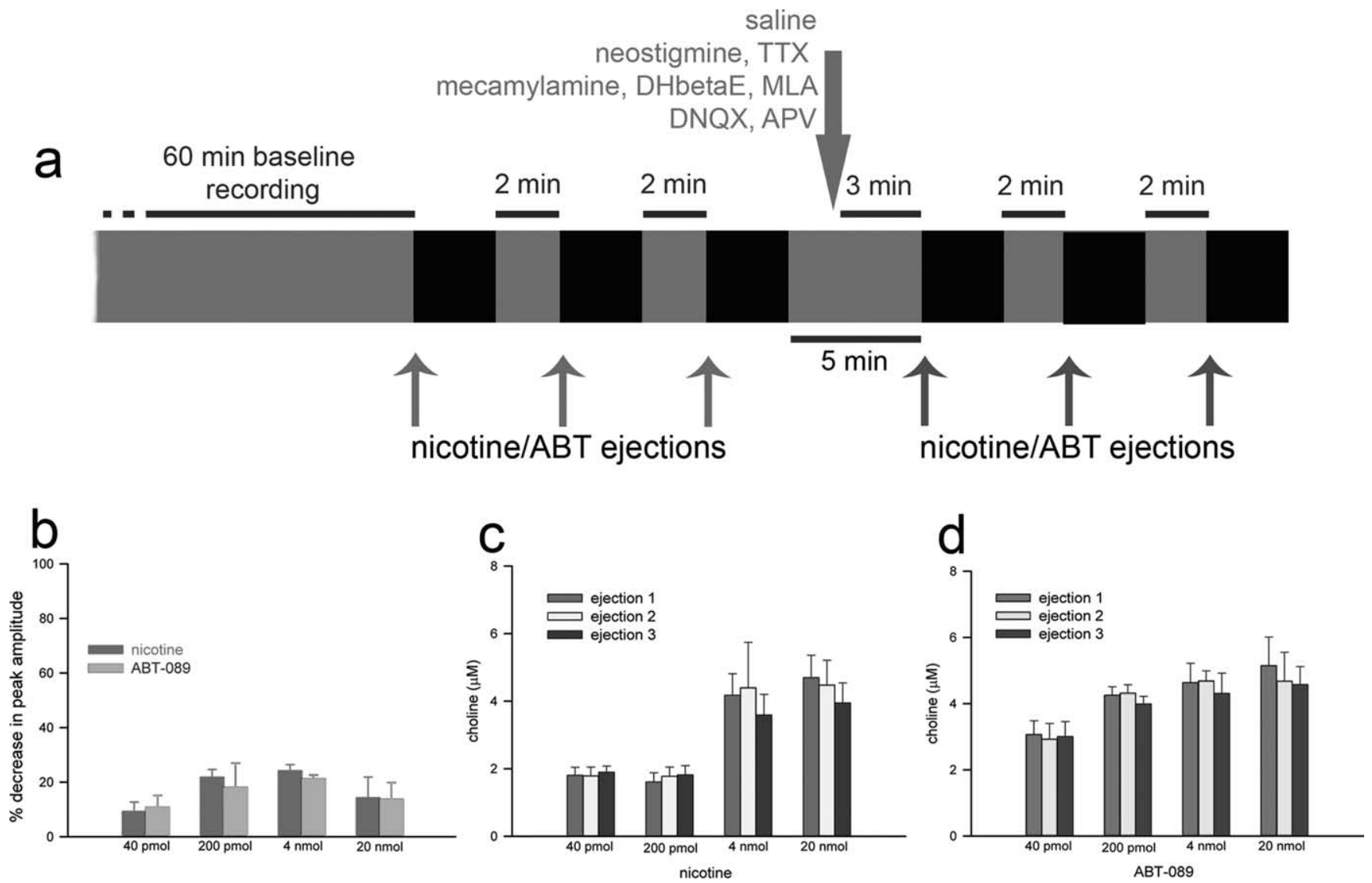

Figure 2. $\boldsymbol{a}$, General experimental design used to determine neuropharmacological mechanisms of nAChR agonist-evoked cholinergic activity. Amperometric recordings of cholinergic or glutamatergic activity were initiated after implantation of enzyme-coated microelectrodes in the mPFC. Experiments began after 60 min of baseline recording. Nicotine or ABT-089 (drug was a between-subject variable) was locally applied by serial pressure ejections, separated by at least 2 min or by the time required to observe an $80 \%$ decline in evoked signal levels. Choline or glutamate signals were recorded after three ejections. To determine the effect of different neuropharmacological manipulations on nicotine or ABT-089-evoked cholinergic or glutamatergic activity, drugs (mecamylamine, neostigmine, DNQX, DH $\beta E, M L A, A P V$, and TTX) were infused into the recording area 2 min after the third pressure ejection. This was followed by a second series of pressure ejections of nicotine or ABT-089, beginning 3 min after drug infusions. The effects of vehicle infusions were also determined to control for effects of repeated administration of the nicotine or ABT-089. $\boldsymbol{b}$, Illustration of the relatively small decreases in choline signal amplitude observed during the second series, compared with the first series, of pressure ejections of the nAChR agonists (main effect of series; see Results). $\boldsymbol{c}, \boldsymbol{d}$, Effects of the three pressure ejections of nicotine (c) or ABT-089 (d), conducted after the infusion of saline (second series of ejections; bars indicate, per dose, amplitudes of first, second, and third pressure ejection after saline infusion; see the three arrows on the right in Fig. 2a). There were no effects of repeated ejection and no interactions between repeated ejection and dose (see Results). Thus, effects of repeated administration of the nAChR agonists did not confound the results generated on the basis of this experimental design. Error bars indicate SEM.

Attenuation choline signals by neostigmine

As illustrated in Figure 4, infusions of neostigmine $(80 \mathrm{pmol})$ completely attenuated choline signals evoked by nicotine $(20$ nmol; saline, $4.67 \pm 1.18 \mu \mathrm{M}$; neostigmine, $0.98 \pm 0.13 \mu \mathrm{M} ; t_{(4)}=$ $3.071, p<0.05)$ or ABT-089 ( $4 \mathrm{nmol}$; saline, $4.31 \pm 0.84$; neostigmine, $\left.0.87 \pm 0.10 ; t_{(8)}=4.247, p<0.01\right)$. These results confirm that the transient increases in choline signal levels indicate increases in choline resulting from hydrolysis of ACh.

\section{Attenuation of choline signals by MEC}

To confirm that choline signals evoked by nicotine and ABT-089 are based on stimulation of nAChRs, the attenuating effects of MEC, a noncompetitive nAChR antagonist, were determined. Figure 5 shows representative choline signal traces evoked by nicotine and ABT-089, recorded after the infusion of saline or MEC ( 80 pmol) (Fig. $5 a-d$ ). Administration of MEC significantly reduced choline signal amplitudes (nicotine: $F_{(1,17)}=$ $65.89, p<0.001$; ABT-089: $\left.t_{(5)}=2.77, p=0.039\right)$. The potency of MEC did not differ between the two nAChR agonists, as indicated by similar effects against $4 \mathrm{nmol}$ nicotine and ABT-089 $\left(t_{(5)}=\right.$ $0.20, p=0.42$ ).
Attenuation of cholinergic signals by $D H \beta E$

As illustrated in Figure $5 e-g, \mathrm{DH} \beta \mathrm{E}$ (for justification of concentration, see Materials and Methods) significantly attenuated ABT-089-evoked choline signals amplitudes $\left(t_{(6)}=18.86, p<\right.$ $0.001)$. Although nicotine-evoked choline signals were also attenuated by $\operatorname{Dh} \beta E\left(t_{(6)}=8.73, p<0.001\right)$, the effect remained relatively small ( $41.23 \pm 5.48 \%$ reduction in amplitude) compared with an $88.37 \pm 4.29 \%$ reduction of the amplitudes of ABT-089-evoked signals $\left(t_{(8)}=6.76, p<0.001\right.$; note that at the concentrations tested, the two nAChR agonist produced similar choline signal amplitudes) (Fig. 3c). Increasing the dose of $\mathrm{DH} \beta \mathrm{E}$ five-fold $(8 \mathrm{nmol})$ did not result in a further reduction of nicotine-evoked choline signal amplitudes (data not shown).

\section{Attenuation of nicotine-evoked cholinergic signal decay rate by $M L A$}

To determine whether nAChR agonist-evoked cholinergic signals are mediated in part by $\alpha 7$ nAChRs, the effects of MLA ( 80 and $800 \mathrm{pmol}$ ) were determined. MLA did not affect nicotine (4 nmol)-evoked choline signal amplitudes $\left(F_{(2,14)}=0.12, p=\right.$ $0.89)$. However, MLA reduced the relatively slow decay rate $\left(t_{50}\right)$ 
of nicotine-evoked cholinergic signals $\left(F_{(2,14)}=9.30, p=0.004\right.$; baseline, $t_{50}$ : $23.06 \pm 6.88 \mathrm{~s}$; decrease in $t_{50}$ relative to the effects of saline, 80 pmol: $8.17 \pm 2.66 \mathrm{~s}$; 800 pmol: $9.30 \pm 2.18 \mathrm{~s}$; multiple comparisons indicated a significant difference between saline and the two concentrations of MLA (both $p<0.01$; LSD), but no significant difference between the effects of the two concentrations of MLA $(p=0.61)$.

\section{Attenuation of cholinergic signals by}

$D N Q X$ and $A P V$

As will be described further below, both nAChR agonists evoked glutamate release and glutamate signal amplitudes were higher after the administration of ABT089 when compared with nicotine. Activation of presynaptic AMPA receptors was demonstrated previously to increase the release of ACh from cortical synaptosomes (Ghersi et al., 2003; Pittaluga et al., 2006). Because presynaptic $\alpha_{4} \beta_{2}$ nAChRs are known to facilitate thalamocortical transmission (Gioanni et al., 1999; Lambe et al., 2003), nAChR agonists have been hypothesized to increase glutamate release via these receptors (Lambe et al., 2003) (see also Radcliffe and Dani 1998). To determine whether AMPA receptor stimulation represents a necessary mediator of $\mathrm{nAChR}$ partial agonist-induced increases in cholinergic activity, the effects of the AMPA receptor antagonist DNQX (20-800 $\mathrm{pmol}$ ) were tested against the cholinergic signals produced by nicotine and ABT-089 ( $4 \mathrm{nmol}$; note that this dose of nicotine and ABT-089 produces equivalent choline signal amplitudes) (Fig. 3c).

DNQX attenuated choline signals evoked by either $\mathrm{nAChR}$ agonist (nicotine: $F_{(1,17)}=5.25, p=0.035$; ABT-089: $F_{(1,23)}$ $=42.80, p<0.001$ ) (Figure 6). The two lower doses of DNQX more completely attenuated ABT-089-evoked signals when compared with nicotine $\left(F_{(1,30)}=5.15\right.$, $p=0.031$ ) (Fig. $6 c$ ). The magnitude of the attenuating effects of the two higher doses of DNQX did not differ between the nAChR agonists.

Infusions of relatively low dose of the NMDA receptor antagonist APV (40 pmol) did not affect the peak amplitudes of nicotine-evoked choline signals $\left(t_{(9)}=\right.$ $1.76, p=0.11)$, but significantly attenuated ABT-089-evoked amplitudes $\left(t_{(9)}=\right.$ 6.73, $p<0.001$ ) (Fig. 7).

\section{Glutamatergic transients evoked by nicotine and ABT-089}

The effects of DNQX and APV described above could be interpreted as indicative of a differential regulation of AMPA and NMDA receptors by the two $\mathrm{nAChR}$ agonists and/or greater in-
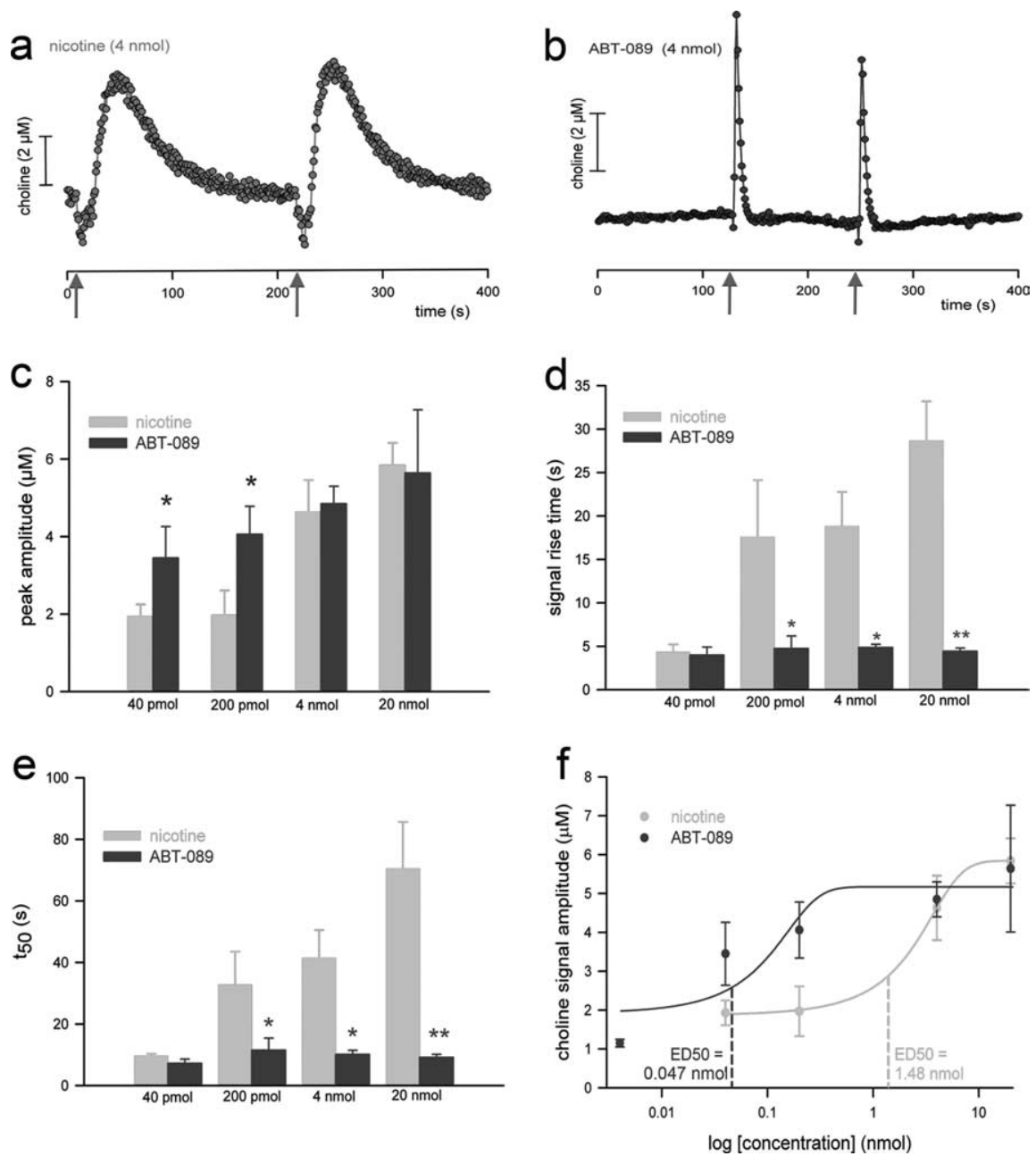

Figure 3. Choline signals evoked by nicotine and ABT-089. $\boldsymbol{a}, \boldsymbol{b}$, Representative traces of cholinergic signals obtained after pressure ejections of nicotine $(4 \mathrm{nmol})$ or ABT-089 $(4 \mathrm{nmol})$. c, Dose-dependent increases in cholinergic activity after nicotine and ABT-089. Compared with nicotine, ABT-089 generated higher signal amplitudes at lower doses (40 and 200 pmol; ${ }^{*} p<0.05$, unpaired $t$ test). $\boldsymbol{d}, \boldsymbol{e}$, Cholinergic signals evoked by ABT-089 were characterized by faster rise times and faster signal decay $\left(t_{50}\right)$ when compared with nicotine $\left(^{*} p<0.05 ;{ }^{* *} p<0.01\right.$, unpaired $t$ test). $f$, Dose-response curves for nicotine- and ABT-089evoked choline signal amplitudes indicate a higher $\mathrm{ED}_{50}$ value for $\mathrm{ABT}-089(0.047 \mathrm{nmol}$; nicotine: $1.48 \mathrm{nmol}$; error bars indicate SEM). As ABT-089 was robustly more potent than nicotine, in terms of peak amplitude (see Introduction for justification of the focus on this measure), an additional low dose ( $4 \mathrm{pmol}$ ) of ABT- 089 needed to be tested in a separate group of animals $(n=3)$ to calculate the $\mathrm{ED}_{50}$ (see data point closest to the abscissa).
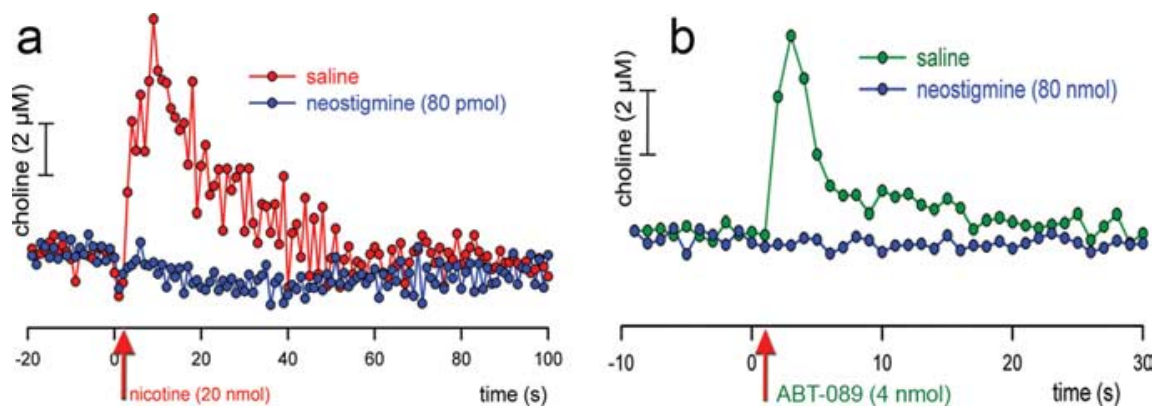

Figure 4. Nicotine- and ABT-089-evoked choline signals reflect choline produced by hydrolysis of ACh. $\boldsymbol{a}, \boldsymbol{b}$, Representative, self-referenced traces of choline signals produced by pressure ejections of nicotine (red, $20 \mathrm{nmol}$ ) or ABT- 089 (green, $4 \mathrm{nmol}$ ) after the infusion of saline or the AChE inhibitor neostigmine ( $80 \mathrm{nmol}$ ) (see Results for statistical findings).

crease in glutamate release by nicotine. Therefore, we used glutamate-sensitive microelectrodes to measure directly glutamate release after the administration of the nAChR agonists. In vitro calibration of glutamate-sensitive microelectrodes $(n=22)$ 

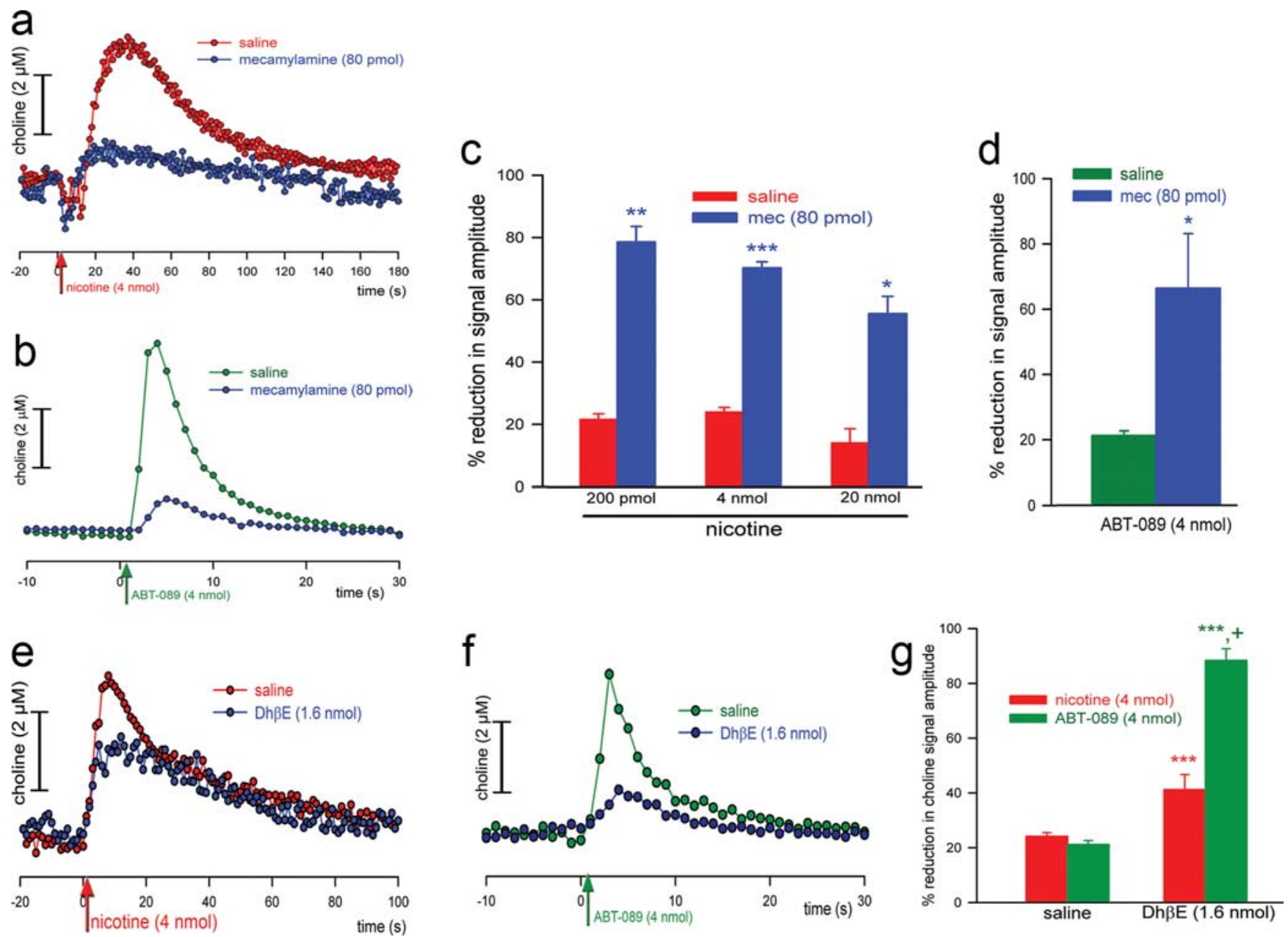

Figure 5. Attenuation of the nAChRagonist-evoked cholinergic signals by MEC and DH $\beta E$. $\boldsymbol{a}, \boldsymbol{b}$, Raw tracings from pressure ejection of nicotine $(\boldsymbol{a})$ or ABT-089 (b) after infusion of saline (nicotine: red; ABT-089: green) or the nAChR antagonist MEC (blue). $\boldsymbol{c}, \boldsymbol{d}$, Bar charts (SEM) depicting the percentage reduction in choline signal amplitudes after MEC $\left({ }^{*} p<0.05 ;{ }^{* *} p<0.01\right.$; ${ }^{* * *} p<0.001$ ), indicating comparable efficacy of MEC against the two nAChR ligands. $\boldsymbol{e}, \boldsymbol{f}$, Raw tracings depicting the effects of DH $\beta E$. At the concentrations tested, nicotine and ABT-089 evoked similar cholinergic signal amplitudes (Fig. 3C). The concentration of $\mathrm{DH} \beta$ E was adjusted to attenuate $>80 \%$ of the amplitude of ABT-089-evoked signals. $\boldsymbol{g}$, At this concentration, DH $\beta$ E inhibited nicotine-evoked signals by only $\sim 20 \% .{ }^{* * *} p<001$, significantly different from saline; ${ }^{+} p<0.05$, significantly different from nicotine.

indicated a sensitivity of $6.42 \pm 0.32 \mathrm{pA} / \mu \mathrm{M}$ for glutamate and an LOD of $218.29 \pm 21.63 \mathrm{nM}$.

The effects of nicotine and ABT-089 on glutamate release were tested at concentrations that revealed greater choline signal amplitudes after the administration of ABT-089 (40 and $200 \mathrm{pmol}$ ) (Fig. 3c). As shown in Figure 8, $a$ and $b$, ABT-089 evoked greater glutamate signal amplitudes than nicotine (main effect of drug: $\left.F_{(1,12)}=11.84, p=0.005\right)$. However, glutamate signal amplitudes did not differ between the two concentrations of either drug (main effect of dose: $F_{(1,12)}=0.115, p=0.75$ ) (Fig. $8 b$ ). Glutamate signal rise time and decay rate did not differ between the two drugs (both $p>0.05$ ).

In past studies, the interpretation of measures of glutamate release in studies using microdialysis was hampered by the finding that blockade of voltage-sensitive sodium channels with TTX only partly attenuated extracellular glutamate levels (Timmerman et al., 1999). In contrast, ABT-089-evoked glutamate signal amplitudes recorded by the present method were reduced by $76.4 \pm 8.1 \%$ after TTX administration $\left(80 \mathrm{pmol} ; t_{(5)}=6.52, p=\right.$ 0.001) (Fig. 8c,d) (Day et al., 2006; Oldenziel et al., 2006).

Finally, we verified that glutamate signals evoked by the two nAChR agonists were sensitive to mecamylamine (Fig. $8 e-g$ ). Mecamylamine significantly reduced glutamate signal ampli- tudes evoked by either drug (nicotine: $t_{(6)}=4.45, p=0.004$; ABT-089: $t_{(5)}=4.01, p=0.04$ ). There was no difference between the effects of mecamylamine on glutamate signals evoked by either drug $\left(t_{(4)}=1.56, p=0.19\right)$.

\section{Discussion}

The main results indicate that ABT-089 was more potent, but not more efficacious, than nicotine in increasing the amplitudes of mPFC cholinergic transients. Furthermore, $\mathrm{DH} \beta \mathrm{E}$ more potently attenuated the amplitudes of cholinergic transients evoked by ABT- 089 when compared with nicotine. Taking into account the finding that mecamylamine was similarly efficacious against the two nAChR agonists and that MLA remained without effect on choline signal amplitudes, these results collectively are consistent with the hypothesis that $\alpha 4 \beta 2^{\star} \mathrm{nAChRs}$ are the primary mediator of $\mathrm{nAChR}$ agonist-evoked cholinergic transients in the $\mathrm{mPFC}$, and that ABT-089 acts primarily at $\alpha 4 \beta 2^{*} \mathrm{nAChRs}$. Additional evidence indicates that the greater amplitudes of cholinergic signals evoked by ABT-089 are matched by greater amplitudes of glutamatergic signals, and that stimulation of NMDA and AMPA receptors is necessary for the manifestation of nAChR-agonist-evoked cholinergic signal amplitudes.

Our results indicate that ionotropic glutamate receptor stim- 

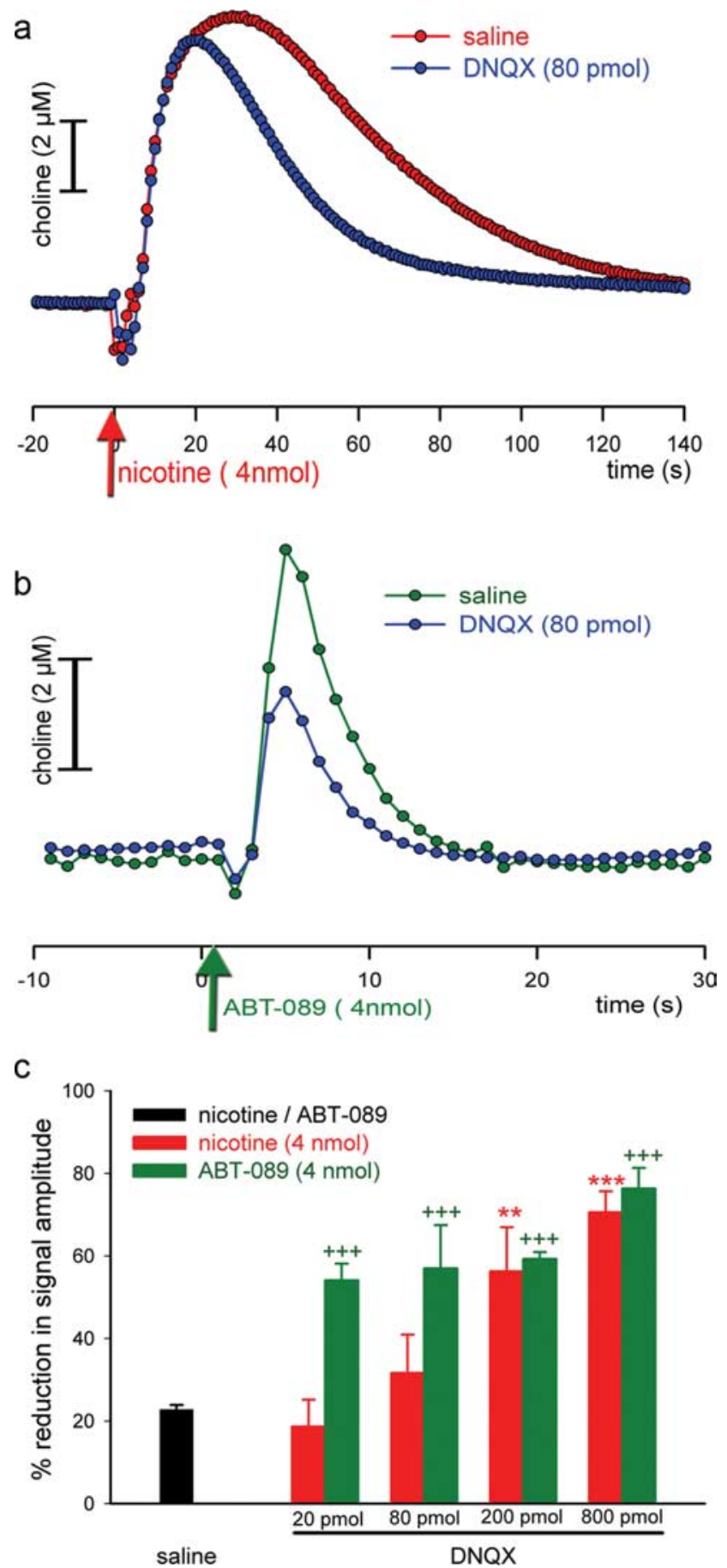

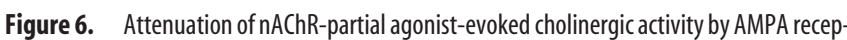
tor blockade. $\boldsymbol{a}, \boldsymbol{b}$, Self-referenced traces depict the effect of DNQX (blue) on cholinergic signals evoked by nicotine (red) or ABT-089 (green). Administration of a low dose (4 nmol) of DNQX (blue traces) attenuated the effect of choline signals produced by pressure ejections of ABT-089 (green trace), but not nicotine (red trace) (4 nmol dose each). c, Bar chart (SEM) summarizing the effects of DNQX doses $(20-800 \mathrm{pmol})$ on choline signal amplitudes evoked by the nAChR agonists (nicotine, red bars; ABT-089, green bars). Higher doses of DNQX similarly attenuated choline signal amplitudes evoked by either nAChR agonist. However, lower doses of DNQX produced greater attenuation of ABT-089-evoked choline signal amplitudes (nicotine, ${ }^{* *} p<$ $\left.0.01,{ }^{* * *} p<001 ; \mathrm{ABT}-089,{ }^{+++} p<0.001\right)$.

ulation is necessary for the demonstration of nAChR agonistinduced increases in cholinergic activity and that ABT-089 produced greater increases in glutamate release than nicotine. Ignoring potential effects on ionotropic glutamate receptor reg-
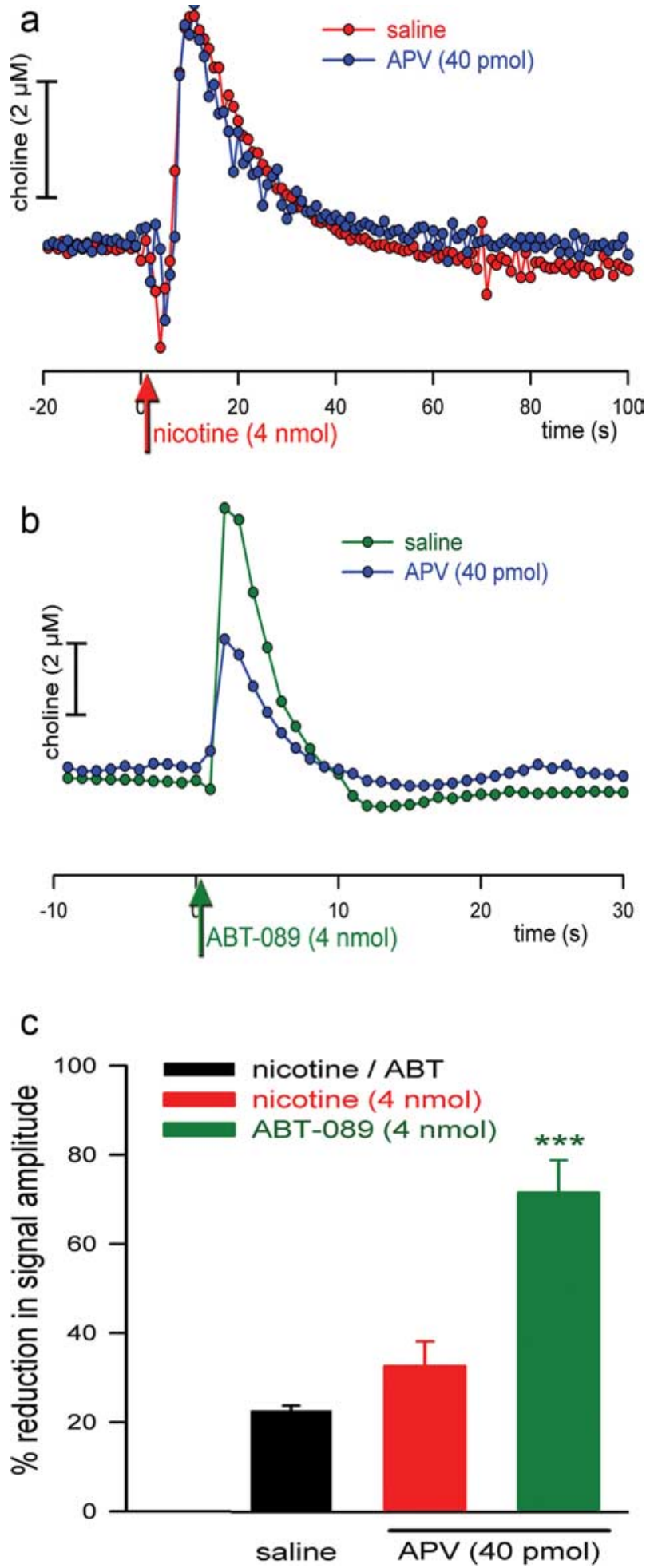

Figure 7. Effects of the NMDA receptor antagonist APV on cholinergic signals evoked by nAChR agonists. $\boldsymbol{a}, \boldsymbol{b}$, Choline signals induced by nicotine $(\boldsymbol{a})$ or ABT-089 ( $\boldsymbol{b}$ ) after infusions of saline (nicotine, red; ABT-089, green) or a low dose of APV ( $40 \mathrm{pmol}$ ). ABT-089, but not nicotineevoked cholinergic activity was attenuated by this dose of APV. c, Reduction in nicotine- and ABT-089-evoked signal amplitudes (SEM) by APV infusions (nicotine, red bars; ABT-089; green bars; ${ }^{* * *} p<0.001$ saline vs APV.

ulation (discussed below), the greater potency of ABT-089 in evoking cholinergic signals could be hypothesized to be secondary to the more potent effects of this drug on glutamate release. The finding that $\mathrm{nAChR}$ agonists produce robust increases in 
a
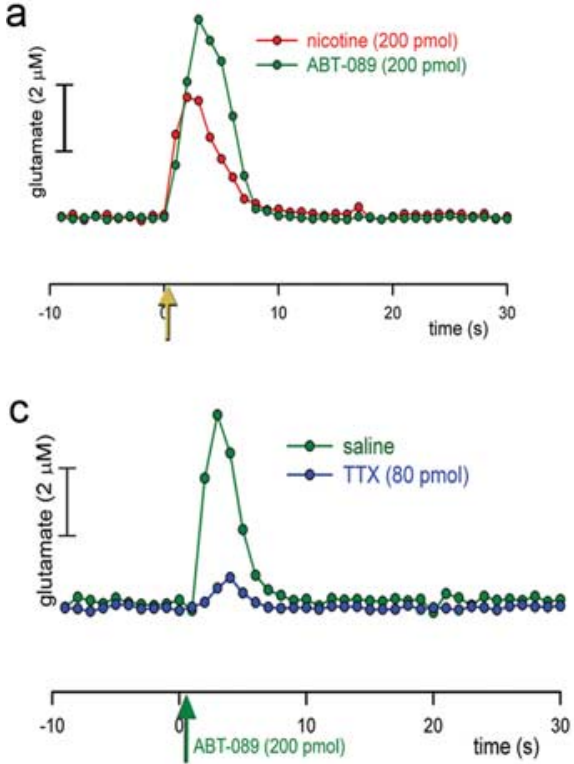

e

咅
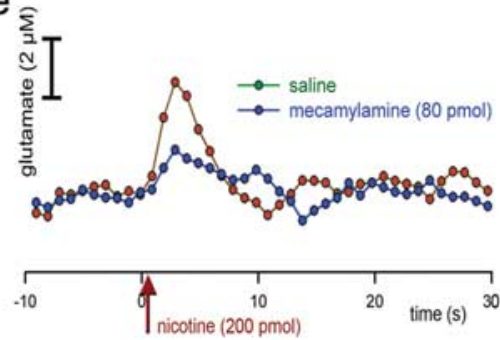

f
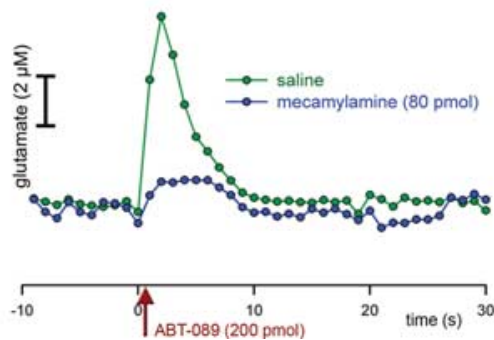

b

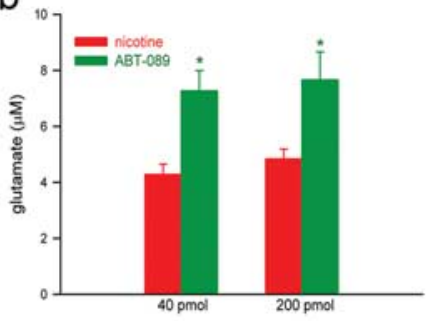

d
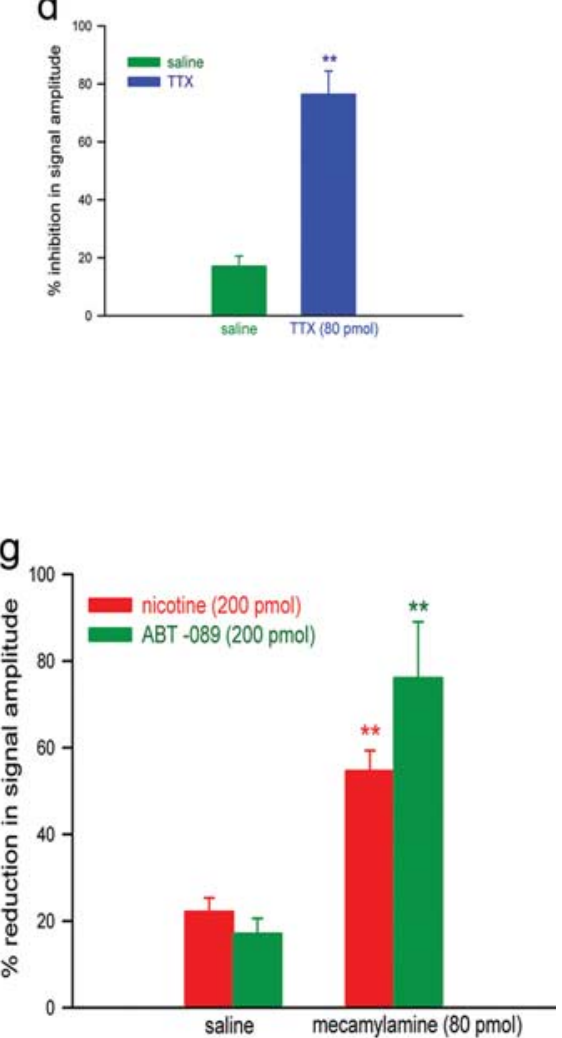

Figure 8. nAChR agonist-induced glutamate release in the mPFC. $\boldsymbol{a}$, Representative, self-referenced traces depict glutamate signals produced by pressure ejection of nicotine (red, 200 pmol) or ABT-089 (green, 200 pmol). $\boldsymbol{b}$, ABT-089 generated greater glutamate signal amplitudes than nicotine $\left({ }^{*} p<0.05\right)$. $c$, Representative traces of ABT-089-evoked glutamate signals after infusion of saline (green) or TTX (80 pmol, blue). $\boldsymbol{d}$, Bar chart depicting the reduction in ABT-089-evoked glutamate signal amplitude by TTX (blue bar; ${ }^{* *} p<0.01$ vs saline). $\boldsymbol{e}-\boldsymbol{g}$, Raw traces $(\boldsymbol{e}, \boldsymbol{f})$ and bar chart $(\boldsymbol{g})$ depicting the attenuation of nicotine and ABT-089-evoked glutamate signal amplitudes by mecamylamine (nicotine, red bars; ABT-089, green bars; ${ }^{* *} p<0.01$ both vs saline).

cortical glutamate release via depolarization-related mechanisms is consistent with results from previous experiments that measured EPSCs after the administration of nicotine to prefrontal slices (Lambe et al., 2003). Lambe et al. (2003) also demonstrated that the nAChR antagonist $\mathrm{DH} \beta \mathrm{E}$ attenuated increases in glutamatergic activity. Because this antagonist is relatively selective for $\alpha 4 \beta 2^{\star}$ and $\alpha 4 \beta 4^{\star}$ nAChRs, but not $\alpha 3 \beta 4^{*}$ nAChRs (Harvey and Luetje, 1996; Harvey et al., 1996), the effects of DH $\beta E$ cannot unequivocally define the nAChR subtype potentially expressed by glutamatergic afferents (Fig. 9). Furthermore, Lambe et al. (2003) showed that removal of thalamic inputs largely attenuated these glutamatergic currents. Collectively, the evidence corresponds with the hypothesis that stimulation of $\alpha 4 \beta 2 / 4^{\star} \mathrm{nAChRs}$ situated on the terminals of the mediodorsal thalamic projections to the mPFC, and perhaps on projections from the amygdala (Sarter and Markowitsch, 1984), account for nicotine-evoked glutamate signals. Furthermore, and considering the pharmacological profile of ABT-089, the present results indicate that ABT- 089 potently stimulates glutamate release via $\alpha 4 \beta 2^{\star} \mathrm{nAChRs}$, and that ionotropic glutamate receptor stimulation is necessary for the manifestation of the amplitudes of cholinergic transients.

The finding that DNQX and APV inhibited choline signals evoked by ABT-089 more robustly when compared with nicotine-evoked signals complicates this hypothesis, as this finding does not readily correspond with the effects on glutamate signal amplitudes. It could be speculated that ABT089 may act through unknown mechanisms, perhaps by modulating glutamatergic ionotropic receptors function to allow glutamate to depolarize cholinergic terminals more potently than is the case after nicotine administration. The data shown in Figure $6 \mathrm{C}$ are consistent with such a scenario. DNQX (20$800 \mathrm{pmol}$ ) attenuated ABT-089-evoked choline signal amplitudes by $\sim 60-80 \%$, but did not exhibit a robust dose-dependent response. In contrast, the effects of DNQX on nicotine-evoked choline signals ranged from a $20 \%$ reduction after $20 \mathrm{pmol}$ to a $\sim 70 \%$ reduction after 800 pmol of DNQX. These observations correspond with the speculation that an ABT-089-induced state of AMPA receptors may have interacted with glutamate release to produce greater cholinergic signal amplitudes.

The importance of such cholinergicglutamatergic interactions was also deduced from experiments that assessed the cognitive effects of nAChR ligands and glutamate receptor antagonists. Specifically, Quarta et al. (2007) reported that blockade of NMDA receptor attenuated the beneficial effects of nicotine on the performance of rats tested in the fivechoice serial reaction time task. The present result that NMDA receptor stimulation is necessary for $\mathrm{nAChR}$ agonist-evoked cholinergic activity, combined with evidence that cholinergic inputs to the mPFC are necessary for the performance of such a task (Dalley et al., 2004), are consistent with the findings reported by Quarta et al. Evidence indicating the necessity of combined activity at nAChR and ionotropic glutamate receptors for learning (Gould and Lewis, 2005) suggests that such glutamatergic-cholinergic interactions generally contribute to fundamental cognitive processes. In the aggregate, these findings corroborate the essential role of glutamatergic-cholinergic interactions for drug-induced cognition enhancement, and the present experimental approach as an early in vivo screening procedure for such compounds.

Administration of MLA did not attenuate nicotine-evoked 

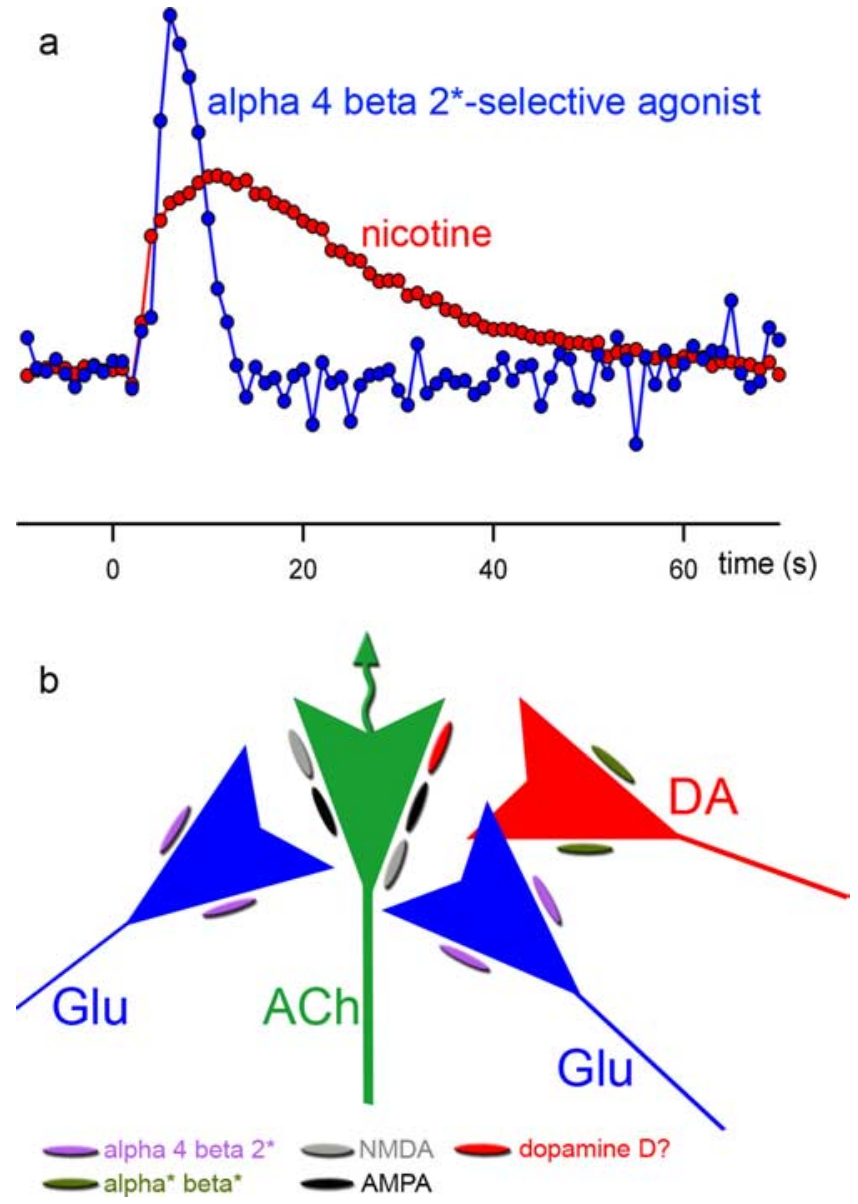

Figure 9. $\quad \boldsymbol{a}$, Schematic illustration of the main characteristics of nicotine and ABT-089evoked transient increases in cholinergic activity. In terms of signal peak amplitudes (see Introduction for justification), ABT-089 was more potent than nicotine. Furthermore, ABT-089evoked cholinergic signals were characterized by faster rise times and decay rates. Such "sharper" cholinergic signals are considered an important neuropharmacological property responsible for the beneficial cognitive efficacy of such compounds (see Introduction). $\boldsymbol{b}$, Parsimonious neuropharmacological mechanisms underlying the differential cholinergic potency of nicotine and ABT-089. Results indicate that glutamate release and stimulation of ionotropic glutamate receptors are necessary for $\mathrm{nAChR}$ agonist-evoked cholinergic activity. The greater cholinergic potency of ABT-089 is attributable to greater selectivity of this drug for $\alpha 4 \beta 2^{*}$ $n A C h R s$. These receptors may be located preferably on the terminals or axons of thalamic, glutamatergic afferents (Lambe et al., 2003; Grilli et al., 2005; Kawai et al., 2007). The cholinergic effects of nicotine may involve additional nAChRs, particularly $\alpha 7 \mathrm{nAChRs}$, and the additional modulatory effects of other neurotransmitters, particularly dopamine, thereby causing the slower decay rate of nicotine-evoked increases in cholinergic activity.

choline signal amplitudes. Assuming that amplitudes represent a critical characteristic for predicting cognitive efficacy (see below), this finding corresponds with behavioral studies demonstrating that MLA neither impaired attentional performance (Grottick and Higgins, 2000) nor antagonized the beneficial effects of nicotine on attention (Blondel et al., 2000), contextual fear conditioning (Davis and Gould, 2006), or stimulusmaintained operant responding (Liu et al., 2007).

Compared with the cholinergic signals produced by ABT-089, nicotine-evoked cholinergic signals required robustly more time to reach peak amplitude and to decay. It seems unlikely that the differences in decay rate were the result of differential effects of the two nAChR agonists on the regulation of the high-affinity CHT, because modification of the capacity of the CHT appear to necessitate relatively prolonged manipulation and may require more time (Sarter and Parikh, 2005; Bruno and Sarter, 2006;
Parikh and Sarter, 2006; Parikh et al., 2006). Furthermore, even the blockade of CHTs with hemicholinium-3 did not produce decay rates as slow as those observed after nicotine administration (Parikh and Sarter 2006). Rather, these relatively slow characteristics of the rise and decay of nicotine-evoked cholinergic signals reflect ongoing and slowly diminishing ACh release. Because nicotine is robustly more potent in releasing dopamine than ABT-089 (Sullivan et al., 1997), we may speculate, as illustrated in Figure 9, that dopaminergic mechanisms mediate the slower decay rate of nicotine-evoked cholinergic activity. Although little remains known about the localization of $\alpha 7 \mathrm{nAChRs}$ in the PFC (but see Azam et al., 2003; Duffy et al., 2007), systemic administration of $\alpha 7$ agonists release dopamine in this region measured in vivo (Summers et al., 1997; Pichat et al., 2007). Evidence suggesting that nicotine can produce sustained release of dopamine by increasing, via stimulation of $\alpha 7 \mathrm{nAChRs}$, the size of the releasable pool of dopamine-storing vesicles (Turner 2004) is consistent with this hypothesis. However, the limited effects of MLA suggest that additional nAChR subtypes are involved in the regulation of nicotine-evoked cholinergic signal decay, possibly involving $\alpha 6 \beta 2^{*}$ nAChRs (Champtiaux et al., 2003).

As summarized by the schematic model shown in Figure 9, the available evidence indicates more potent (in terms of peak amplitude) and "sharper" cholinergic transients evoked by ABT-089 when compared with nicotine. Furthermore, the available evidence is consistent with the hypothesis that glutamate release and AMPA and NMDA receptor stimulation necessarily mediate ABT-089-evoked signals and the amplitude of nicotine-evoked cholinergic transients. Thus, $\alpha 4 \beta 2^{\star}$ nAChRs represent the main nicotinic receptor subtype involved in the manifestation of cholinergic signal amplitudes (Summers et al., 1995). The exact mechanism underlying the ongoing ACh release that is evoked by nicotine, but not ABT-089, and that is likely responsible for the slow decay rate of nicotine-evoked signals, remains poorly understood.

Finally, and as the development of methods for the effective screening of cognition enhancers has remained a challenge (Sarter 2006), the present neuropharmacological approach may be useful in efforts designed to characterize, at an early stage of screening, putative cognition enhancers. This view relies on the validity of the general hypothesis that cholinergic effects constitute a necessary component of the neuropharmacological mechanisms mediating drug-induced cognition enhancement (Potter et al., 2006). We have recently demonstrated that the detection of cues is mediated by cholinergic transients in the MPFC (Parikh et al., 2007). The characteristics of these transients correspond well with ABT-089-evoked cholinergic transients, but not with the ongoing ACh release, indicated by slow cholinergic signal decay rates, that was evoked by nicotine. As the facilitation of attentional functions has been hypothesized to involve amplification of the processing of thalamic inputs (Metherate and Weinberger, 1989; Metherate et al., 1990; Hasselmo and McGaughy, 2004; Sarter et al., 2005), the potent and temporally precise cholinergic modulation of sensory inputs by compounds such as ABT-089 may predict an enhancement of detection processes. In contrast, a more prolonged and temporally less defined cholinergic signal may only support a very limited enhancement of attentional functions or even interfere with the enhanced processing of selected thalamic inputs in the cortex. Clearly, the usefulness of these predictions and of the present experimental approach as a screening tool depend on the demonstration that equivalent modulation of detection-evoked signals are observed after sys- 
temic administration of $\mathrm{nAChR}$ agonists in task-performing animals.

\section{References}

Apparsundaram S, Martinez V, Parikh V, Kozak R, Sarter M (2005) Increased capacity and density of choline transporters situated in synaptic membranes of the right medial prefrontal cortex of attentional taskperforming rats. J Neurosci 25:3851-3856.

Azam L, Winzer-Serhan U, Leslie FM (2003) Co-expression of alpha7 and beta2 nicotinic acetylcholine receptor subunit mRNAs within rat brain cholinergic neurons. Neuroscience 119:965-977.

Blondel A, Sanger DJ, Moser PC (2000) Characterization of the effects of nicotine in the five-choice serial reaction time task in rats: antagonist studies. Psychopharmacology 149:293-305.

Bruno JP, Sarter M (2006) Presynaptic regulation and modulation of acetylcholine release. In: The brain cholinergic system (Giacobini E, Pepeu G, eds), pp 99-111. Abingdon, UK: Taylor and Francis.

Bruno JP, Gash C, Martin B, Zmarowski A, Pomerleau F, Burmeister J, Huetti P, Gerhardt GA (2006) Second-by-second measurement of acetylcholine release in prefrontal cortex. Eur J Neurosci 24:2749-2757.

Burmeister JJ, Gerhardt GA (2001) Self-referencing ceramic-based multisite microelectrodes for the detection and elimination of interferences from the measurement of L-glutamate and other analytes. Anal Chem 73:1037-1042.

Burmeister JJ, Pomerleau F, Palmer M, Day BK, Huettl P, Gerhardt GA (2002) Improved ceramic-based multisite microelectrode for rapid measurements of L-glutamate in the CNS. J Neurosci Methods 119:163-171.

Cao YJ, Surowy CS, Puttfarcken PS (2005) Different nicotinic acetylcholine receptor subtypes mediating striatal and prefrontal cortical $[3 \mathrm{H}]$ dopamine release. Neuropharmacology 48:72-79.

Champtiaux N, Gotti C, Cordero-Erausquin M, David DJ, Przybylski C, Léna C, Clementi F, Moretti M, Rossi FM, Le Novère N, McIntosh JM, Gardier AM, Changeux JP (2003) Subunit composition of functional nicotinic receptors in dopaminergic neurons investigated with knock-out mice. J Neurosci 23:7820-7829.

Dalley JW, Theobald DE, Bouger P, Chudasama Y, Cardinal RN, Robbins TW (2004) Cortical cholinergic function and deficits in visual attentional performance in rats following $192 \mathrm{IgG}$-saporin-induced lesions of the medial prefrontal cortex. Cereb Cortex 14:922-932.

Dani JA, Bertrand D (2007) Nicotinic acetylcholine receptors and nicotinic cholinergic mechanisms of the central nervous system. Annu Rev Pharmacol Toxicol 47:699-729.

Davis JA, Gould TJ (2006) The effects of DHBE and MLA on nicotineinduced enhancement of contextual fear conditioning in C57BL/6 mice. Psychopharmacology 184:345-352.

Day BK, Pomerleau F, Burmeister JJ, Huettl P, Gerhardt GA (2006) Microelectrode array studies of basal and potassium-evoked release of L-glutamate in the anesthetized rat brain. J Neurochem 96:1626-1635.

Decker MW, Bannon AW, Curzon P, Gunther KL, Brioni JD, Holladay MW, Lin NH, Li Y, Daanen JF, Buccafusco JJ, Prendergast MA, Jackson WJ, Arneric SP (1997) ABT-089 [2-methyl-3-(2-(S)-pyrrolidinylmethoxy)pyridine dihydrochloride]: II. A novel cholinergic channel modulator with effects on cognitive performance in rats and monkeys. J Pharmacol Exp Ther 283:247-258.

Duffy AM, Milner TA, Pickel VM (2007) Electron microscopic immunolabeling of the alpha-7 nicotinic acetylcholine receptor subunit in the rat and mouse medial prefrontal cortex. Soc Neurosci Abstr 33:607.20.

Friedemann MN, Gerhardt GA (1992) Regional effects of aging on dopaminergic function in the Fischer-344 rat. Neurobiol Aging 13:325-332.

Ghersi C, Bonfanti A, Manzari B, Feligioni M, Raiteri M, Pittaluga A (2003) Pharmacological heterogeneity of release-regulating presynaptic AMPA/ kainate receptors in the rat brain: study with receptor antagonists. Neurochem Int 42:283-292.

Gill TM, Sarter M, Givens B (2000) Sustained visual attention performanceassociated prefrontal neuronal activity: evidence for cholinergic modulation. J Neurosci 20:4745-4757.

Gioanni Y, Rougeot C, Clarke PB, Lepouse C, Thierry AM, Vidal C (1999) Nicotinic receptors in the rat prefrontal cortex: increase in glutamate release and facilitation of mediodorsal thalamo-cortical transmission. Eur J Neurosci 11:18-30.

Girod R, Barazangi N, McGehee D, Role LW (2000) Facilitation of glutama- tergic neurotransmission by presynaptic nicotinic acetylcholine receptors. Neuropharmacology 39:2715-2725.

Gould TJ, Lewis MC (2005) Coantagonism of glutamate receptors and nicotinic acetylcholinergic receptors disrupts fear conditioning and latent inhibition of fear conditioning. Learn Mem 12:389-398.

Greenwald AG, Gonzalez R, Harris RJ, Guthrie D (1996) Effect sizes and p values: what should be reported and what should be replicated? Psychophysiology 33:175-183.

Grilli M, Parodi M, Raiteri M, Marchi M (2005) Chronic nicotine differentially affects the function of nicotinic receptor subtypes regulating neurotransmitter release. J Neurochem 93:1353-1360.

Grottick AJ, Higgins GA (2000) Effect of subtype selective nicotinic compounds on attention as assessed by the five-choice serial reaction time task. Behav Brain Res 117:197-208.

Harvey SC, Luetje CW (1996) Determinants of competitive antagonist sensitivity on neuronal nicotinic receptor beta subunits. J Neurosci 16:3798-3806

Harvey SC, Maddox FN, Luetje CW (1996) Multiple determinants of dihydro-beta-erythroidine sensitivity on rat neuronal nicotinic receptor alpha subunits. J Neurochem 67:1953-1959.

Hasselmo ME, McGaughy J (2004) High acetylcholine levels set circuit dynamics for attention and encoding and low acetylcholine levels set dynamics for consolidation. Prog Brain Res 145:201-231.

Hernandez CM, Terry Jr AV (2005) Repeated nicotine exposure in rats: effects on memory function, cholinergic markers and nerve growth factor. Neuroscience 130:997-1012.

Kawai H, Lazar R, Metherate R (2007) Nicotinic control of axon excitability regulates thalamocortical transmission. Nat Neurosci 10:1168-1175.

Kozak R, Bruno JP, Sarter M (2006) Augmented prefrontal acetylcholine release during challenged attentional performance. Cereb Cortex 16:9-17.

Kuroda M, Murakami K, Kishi K, Price JL (1995) Thalamocortical synapses between axons from the mediodorsal thalamic nucleus and pyramidal cells in the prelimbic cortex of the rat. J Comp Neurol 356:143-151.

Lambe EK, Picciotto MR, Aghajanian GK (2003) Nicotine induces glutamate release from thalamocortical terminals in prefrontal cortex. Neuropsychopharmacology 28:216-225.

Liu X, Palmatier MI, Caggiula AR, Donny EC, Sved AF (2007) Reinforcement enhancing effect of nicotine and its attenuation by nicotinic antagonists in rats. Psychopharmacology 194:463-473.

Marchi M, Raiteri M (1996) Nicotinic autoreceptors mediating enhancement of acetylcholine release become operative in conditions of "impaired" cholinergic presynaptic function. J Neurochem 67:1974-1981.

Marchi M, Lupinacci M, Bernero E, Bergaglia F, Raiteri M (1999) Nicotinic receptors modulating $\mathrm{ACh}$ release in rat cortical synaptosomes: role of $\mathrm{Ca}^{2+}$ ions in their function and desensitization. Neurochem Int 34:319-328.

McGaughy J, Kaiser T, Sarter M (1996) Behavioral vigilance following infusions of 192 IgG-saporin into the basal forebrain: selectivity of the behavioral impairment and relation to cortical AChE-positive fiber density. Behav Neurosci 110:247-265.

McGaughy J, Decker MW, Sarter M (1999) Enhancement of sustained attention performance by the nicotinic acetylcholine receptor agonist ABT418 in intact but not basal forebrain-lesioned rats. Psychopharmacology 144:175-182.

Metherate R, Weinberger NM (1989) Acetylcholine produces stimulusspecific receptive field alterations in cat auditory cortex. Brain Res 480:372-377.

Metherate R, Ashe JH, Weinberger NM (1990) Acetylcholine modifies neuronal acoustic rate-level functions in guinea pig auditory cortex by an action at muscarinic receptors. Synapse 6:364-368.

Mitchell KM (2004) Acetylcholine and choline amperometric enzyme sensors characterized in vitro and in vivo. Anal Chem 76:1098-1106.

Motulsky HJ, Ransnas LA (1987) Fitting curves to data using nonlinear regression: a practical and nonmathematical review. FASEB J 1:365-374.

Oldenziel WH, Dijkstra G, Cremers TI, Westerink BH (2006) In vivo monitoring of extracellular glutamate in the brain with a microsensor. Brain Res 1118:34-42.

Parikh V, Sarter M (2006) Cortical choline transporter function measured in vivo using choline-sensitive microelectrodes: clearance of endogenous and exogenous choline and effects of removal of cholinergic terminals. J Neurochem 97:488-503. 
Parikh V, Pomerleau F, Huettl P, Gerhardt GA, Sarter M, Bruno JP (2004) Rapid assessment of in vivo cholinergic transmission by amperometric detection of changes in extracellular choline levels. Eur J Neurosci 20:1545-1554.

Parikh V, Apparsundaram S, Kozak R, Richards JB, Sarter M (2006) Reduced expression and capacity of the striatal high-affinity choline transporter in hyperdopaminergic mice. Neuroscience 141:379-389.

Parikh V, Kozak R, Martinez V, Sarter M (2007) Prefrontal acetylcholine controls cue detection on multiple time scales. Neuron 56:141-154.

Pichat P, Bergis OE, Terranova JP, Urani A, Duarte C, Santucci V, Gueudet C, Voltz C, Steinberg R, Stemmelin J, Oury-Donat F, Avenet P, Griebel G, Scatton B (2007) SSR180711, a novel selective alpha7 nicotinic receptor partial agonist: (II) efficacy in experimental models predictive of activity against cognitive symptoms of schizophrenia. Neuropsychopharmacology 32:17-34.

Pittaluga A, Feligioni M, Longordo F, Luccini E, Raiteri M (2006) Trafficking of presynaptic AMPA receptors mediating neurotransmitter release: neuronal selectivity and relationships with sensitivity to cyclothiazide. Neuropharmacology 50:286-296.

Potter AS, Newhouse PA, Bucci DJ (2006) Central nicotinic cholinergic systems: a role in the cognitive dysfunction in attention-deficit/hyperactivity disorder? Behav Brain Res 175:201-211.

Quarta D, Naylor CG, Morris HV, Patel S, Genn RF, Stolerman IP (2007) Different effects of ionotropic and metabotropic glutamate receptor antagonists on attention and the attentional properties of nicotine. Neuropharmacology 53:421-430.

Quirion R, Richard J, Wilson A (1994) Muscarinic and nicotinic modulation of cortical acetylcholine release monitored by in vivo microdialysis in freely moving adult rats. Synapse 17:92-100.

Radcliffe KA, Dani JA (1998) Nicotinic stimulation produces multiple forms of increased glutamatergic synaptic transmission. J Neurosci 18:7075-7083.

Risso F, Grilli M, Parodi M, Bado M, Raiteri M, Marchi M (2004) Nicotine exerts a permissive role on NMDA receptor function in hippocampal noradrenergic terminals. Neuropharmacology 47:65-71.

Robinson SE, Vann RE, Britton AF, O’Connell MM, James JR, Rosecrans JA (2007) Cellular nicotinic receptor desensitization correlates with nicotine-induced acute behavioral tolerance in rats. Psychopharmacology 192:71-78.

Rousseau SJ, Jones IW, Pullar IA, Wonnacott S (2005) Presynaptic alpha7 and non-alpha7 nicotinic acetylcholine receptors modulate $[3 \mathrm{H}] \mathrm{d}$ aspartate release from rat frontal cortex in vitro. Neuropharmacology 49:59-72.

Rueter LE, Anderson DJ, Briggs CA, Donnelly-Roberts DL, Gintant GA, Gopalakrishnan M, Lin NH, Osinski MA, Reinhart GA, Buckley MJ, Martin RL, McDermott JS, Preusser LC, Seifert TR, Su Z, Cox BF, Decker MW, Sullivan JP (2004) ABT-089: pharmacological properties of a neuronal nicotinic acetylcholine receptor agonist for the potential treatment of cognitive disorders. CNS Drug Rev 10:167-182.
Sarter M (2006) Preclinical research into cognition enhancers. Trends Pharmacol Sci 27:602-608

Sarter M, Markowitsch HJ (1984) Collateral innervation of the medial and lateral prefrontal cortex by amygdaloid, thalamic, and brain-stem neurons. J Comp Neurol 224:445-460.

Sarter M, Parikh V (2005) Choline transporters, cholinergic transmission and cognition. Nature Rev Neurosci 6:48-56.

Sarter M, Hasselmo ME, Bruno JP, Givens B (2005) Unraveling the attentional functions of cortical cholinergic inputs: interactions between signal-driven and top-down cholinergic modulation of signal detection. Brain Res Rev 48:98-111.

Sarter M, Gehring WJ, Kozak R (2006) More attention must be paid: the neurobiology of attentional effort. Brain Res Rev 51:145-160.

Shearman E, Rossi S, Sershen H, Hashim A, Lajtha A (2005) Locally administered low nicotine-induced neurotransmitter changes in areas of cognitive function. Neurochem Res 30:1055-1066.

Sullivan JP, Donnelly-Roberts D, Briggs CA, Anderson DJ, Gopalakrishnan M, Xue IC, Piattoni-Kaplan M, Molinari E, Campbell JE, McKenna DG Gunn DE, Lin NH, Ryther KB, He Y, Holladay MW, Wonnacott S, Williams M, Arneric SP (1997) ABT-089 [2-methyl-3-(2-(S)-pyrrolidinylmethoxy)pyridine]: I. A potent and selective cholinergic channel modulator with neuroprotective properties. J Pharmacol Exp Ther 283:235-246.

Summers KL, Lippiello P, Verhulst S, Giacobini E (1995) 5-fluoronicotine, noranhydroecgonine, and pyridyl-methylpyrrolidine release acetylcholine and biogenic amines in rat cortex in vivo. Neurochem Res 20:1089-1094.

Summers KL, Kem WR, Giacobini E (1997) Nicotinic agonist modulation of neurotransmitter levels in the rat frontoparietal cortex. Jpn J Pharmacol 74:139-146.

Timmerman W, Cisci G, Nap A, de Vries JB, Westerink BH (1999) Effects of handling on extracellular levels of glutamate and other amino acids in various areas of the brain measured by microdialysis. Brain Res $833: 150-160$

Turner TJ (2004) Nicotine enhancement of dopamine release by a calciumdependent increase in the size of the readily releasable pool of synaptic vesicles. J Neurosci 24:11328-11336.

Ulus IH, Buyukuysal RL, Wurtman RJ (1992) N-methyl-D-aspartate increases acetylcholine release from rat striatum and cortex: its effect is augmented by choline. J Pharmacol Exp Ther 261:1122-1128.

Wilens TE, Decker MW (2007) Neuronal nicotinic receptor agonists for the treatment of attention-deficit/hyperactivity disorder: focus on cognition. Biochem Pharmacol 74:1212-1223.

Wilens TE, Verlinden MH, Adler LA, Wozniak PJ, West SA (2006) ABT089, a neuronal nicotinic receptor partial agonist, for the treatment of attention-deficit/hyperactivity disorder in adults: results of a pilot study. Biol Psychiatry 59:1065-1070.

Wonnacott S (1997) Presynaptic nicotinic ACh receptors. Trends Neurosci 20:92-98. 